\title{
Blindness and Visual Impairment in Germany
}

\author{
A Slight Fall in Prevalence
}

Robert P. Finger, Bernd Bertram, Christian Wolfram, Frank G. Holz

\section{SUMMARY}

Background: Some $70 \%$ of all cases of blindness in Germany are due to diseases of old age. As the population at large is aging, the prevalence of blindness and visual impairment would be expected to rise. To assess this, we studied prevalence trends in Germany over the past three decades.

Methods: We calculated the age- and sex-standardized prevalence of blindness in Germany using data from the archive of the blind registry of the Rhineland Regional Council (Landschaftsverband Rheinland, LVR) for the years 1978 to 2006. We then validated the findings with the aid of data on blindness and visual impairment from the Statistics on Severe Disability (Schwerbehindertenstatistik, SBS) that are published periodically by the German Federal Statistical Office.

Results: The number of registered blind persons in the Rhineland increased from 10665 in 1978 to 12706 in 1987 and 15766 in 1997, but it changed little thereafter, remaining at 15725 in 2006. There was a corresponding trend in the prevalence of blindness in the Rhineland, which rose from 116.8 to 165.6 per 100000 persons from 1978 to 1997 but was roughly the same, at 163.1 per 100000 persons, in 2006. The SBS data on blindness and visual impairment reveal a decline in prevalence from 392 to 372 per 100000 persons between 1987 and 2005. The standardized prevalence rates for blindness and visual impairment in Germany have been declining slowly since about 1997.

Discussion: Blindness and visual impairment have become slightly less common in Germany, even though the population is aging. This may be due, at least in part, to better eye health care.

\section{- Cite this as}

Finger RP, Bertram B, Wolfram C, Holz FG: Blindness and visual impairment in Germany-a slight fall in prevalence. Dtsch Arztebl Int 2012; 109(27-28): 484-9. DOI: 10.3238/arztebl.2012.0484

\footnotetext{
Department of Ophthalmology, University of Bonn: Dr. med. Finger, Prof. Dr. med. Holz Centre for Eye Research Australia, University of Melbourne, Australien: Dr. med. Finger Ophthalmological Practice, Aachen: Prof. Dr. med. Bertram
}

Department of Ophthalmology, Johannes Gutenberg-University, Mainz: Dr. med. Wolfram $\mathrm{n}$ all the industrialized countries, the main causes of blindness and visual impairment are age-related macular degeneration (AMD), glaucoma, and diabetic retinopathy (1). The prevalence of these eye diseases increases considerably with age (1). Since life expectancy has risen markedly in the past few decades, and the post-war baby-boom generation has now reached the relevant age group for these diseases, we must expect-assuming all other factors remain the same - that the numbers of people who are blind or visually impaired will increase and the need for eye health care will rise $(2,3)$.

Unlike a number of other countries $(4,5)$, Germany has no national registry of the blind, but data do exist for individual federal states (Länder). The largest dataset in Germany is contained in the archive of the blind registry of the Rhineland Regional Council (LVR, Landschaftsverband Rheinland), which is responsible for the roughly 9.5 million inhabitants of the Rhineland (1). Extrapolations to the whole of Germany from the data of this archive of the North Rhine Regional Council, taking into account demographic trends, predict an increase in the number of annual new cases of blindness in Germany by 25\%, from about 10000 in 2010 to 12500 in 2030 (6). Projections of the expected incidence of blindness for other industrialized countries with a mainly white population show a similar rise and a distinctly higher risk for women of losing vision in old age (7). That women are at greater risk of blindness is a worldwide phenomenon that at present remains inadequately explained and is only partly related to their longer life expectancy (8).

Most projections assume that mortality and health care remain the same in the population under consideration; dynamic factors that will affect future trends are usually left out of account. Retrospective analyses, therefore, better allow examination of the dynamics of trends in the health of the general population. The study reported here presents the trend in the prevalence of blindness and visual impairment over the past few decades for the Rhineland. Out of a very large cohort from the administrative area of the North Rhine Regional Council, data on blindness are available for the years 1978, 1987, 1997, and $2006(1,9)$. 
Trends in numbers of blind persons and causes of blindness in the Rhineland 1978-2006

\begin{tabular}{l|c|c|c|c} 
& \multicolumn{1}{|c|}{1978} & 1987 & 1997 & 2006 \\
\hline Reference population (Rhineland) ( $\mathrm{n})$ & 9.13 million & 8.94 million & 9.52 million & 9.65 million \\
\hline Total number of registered blind persons & 10665 & 12706 & 15766 & 15725 \\
\hline Number of blind persons/100 000 population & 116.8 & 142.1 & 165.6 & 163 \\
\hline Causes (\%) & & & & 40.7 \\
\hline Age-related macular degeneration & 20.3 & 26.8 & 32.5 & 15.4 \\
\hline Glaucoma and optic nerve atrophy & 24.6 & 21.0 & 20.1 & 9.7 \\
\hline Diabetic eye diseases & 6.9 & 8.1 & 8.9 & 5.3 \\
\hline High myopia/retinal detachment & 15.9 & 13.4 & 10.2 & 7.0 \\
\hline Retinitis pigmentosa/inherited eye disease & 7.8 & 8.2 & 7.6 & 19.5 \\
\hline Other & 24.5 & 22.5 & 20.7 & \\
\hline
\end{tabular}

\section{Methods}

\section{Definition of blindness and visual impairment}

Both the LVR and the social security offices (which issue disability allowances other than blindness allowance, e.g., exemption from public transport fares, tax relief) define blindness as it is defined in German law. In Germany, blindness is legally defined as a maximum visual acuity of 0.02 ( $1 / 50^{\text {th }}$ of normal visual acuity) in the better eye, or an equivalent disturbance of vision. Examples of the latter are a visual acuity of less than 0.033 and a residual visual field not exceeding $30^{\circ}$, or a visual acuity of less than 0.1 and a binocular visual field of no more than $7.5^{\circ}$ in any direction. Severe visual impairment is not legally defined and is commonly defined as visual acuity in the range of 0.03 to 0.05 or an equivalent impairment such as better visual acuity combined with extensive limitation of the visual field. The LVR dataset presented here relates only to blind persons, while the Statistics on Severe Disability (Schwerbehindertenstatistik, SBS) from the social security offices include both those who are blind and those with severe visual impairment.

\section{Data from the Rhineland Regional Council (LVR)}

The data from the archive of the blind registry of the LVR for the reference year 2006 were compared with data from 1978, 1987, and 1997. The method of data collection has been described in detail elsewhere and will only be briefly outlined here $(1,9)$. Blindness allowance and disability allowance for severe visual impairment are granted when an application is made and authorized. Since the category "severe visual impairment" was only introduced by the LVR in 1998, and up to this time support was provided only for those registered blind, only blindness is considered in this study; severe visual impairment is not included. The application form (the current version of which is accessible at https://formulare.lvr.de) includes sociodemographic data plus a statement from a consultant ophthalmologist. This statement provides among other things visual acuity of both eyes with optimal correction, a visual field report (optional), the main cause of blindness, and any other disease affecting the eyes. The main cause of the blindness or visual impairment is stated by the ophthalmologist on the application form in free text. This free text was categorized in several steps.

At present no estimates exist of the completeness of the LVR blind registry. Because blindness allowance is quite high (more than 400 euro/month), tax-free and largely irrespective of other income and the receiver's financial status, a high rate of registration may be assumed (1). Moreover, the professional medical societies recommend informing patients of the possibility of applying for blindness allowance or support for severe visual impairment. Hence, there is widespread awareness of the availability of this support, allowing us to assume that the overall rate of registration is high.

Data for the LVR's blind registry are only available for the years 1997 and 2006, and only summary statistics are available for the years prior to 1997, as presented in Table 1. For this reason, prevalence rates were calculated only for 1997 and 2006. From 2006 onwards no data exist as to the main causes of blindness, since these are collected manually and do not form part of the annual reports. For this reason, more recent years were not included in this study.

\section{Validation of the LVR data}

In order to further validate trends in blindness and visual impairment in the population, we used data from the social security offices on severe disabilities (registration as disabled on the grounds of blindness and visual impairment) for the administrative districts of Düsseldorf and Cologne, which correspond to the area covered by the LVR. These data are based on the three disabilities seen by the social administration as the most important disabilities included in the statistics. 
Prevalence of blindness in the Rhineland in 1997 and 2006, stratified by age and sex, based on the LVR dataset (per 100000 persons)

\begin{tabular}{|c|c|c|c|c|c|c|}
\hline \multirow[b]{2}{*}{ Age group } & \multicolumn{3}{|c|}{1997} & \multicolumn{3}{|c|}{2006} \\
\hline & Male & Female & All & Male & Female & All \\
\hline$\leq 20$ years & 38.79 & 36.12 & 37.49 & 49.53 & 43.83 & 46.68 \\
\hline $95 \% \mathrm{Cl}$ & $\begin{array}{c}35.05- \\
42.71\end{array}$ & $\begin{array}{c}32.52- \\
40.12\end{array}$ & $\begin{array}{c}34.89- \\
40.29\end{array}$ & $\begin{array}{c}45.32- \\
54.13\end{array}$ & $\begin{array}{l}39.89- \\
48.17\end{array}$ & $\begin{array}{c}43.76- \\
49.80\end{array}$ \\
\hline$>20$ to $<60$ years & 60.56 & 50.64 & 55.64 & 68.19 & 60.11 & 64.15 \\
\hline $95 \% \mathrm{Cl}$ & $\begin{array}{l}57.71- \\
63.55\end{array}$ & $\begin{array}{c}48.01- \\
53.40\end{array}$ & $\begin{array}{l}53.69- \\
57.66\end{array}$ & $\begin{array}{c}65.11- \\
71.41\end{array}$ & $\begin{array}{c}57.22- \\
63.14\end{array}$ & $\begin{array}{l}62.03- \\
66.35\end{array}$ \\
\hline 60 to $<80$ years & 244.11 & 297.16 & 273.86 & 219.83 & 251.33 & 236.65 \\
\hline $95 \% \mathrm{Cl}$ & $\begin{array}{c}233.43- \\
255.27\end{array}$ & $\begin{array}{c}286.69- \\
308.01\end{array}$ & $\begin{array}{l}266.30- \\
281.63\end{array}$ & $\begin{array}{c}210.46- \\
229.62\end{array}$ & $\begin{array}{c}241.94- \\
261.09\end{array}$ & $\begin{array}{c}229.96- \\
243.53\end{array}$ \\
\hline$\geq 80$ years & 1604.51 & 2212.16 & 2056.95 & 1117.67 & 1739.73 & 1556.47 \\
\hline $95 \% \mathrm{Cl}$ & $\begin{array}{c}1523.78- \\
1689.45\end{array}$ & $\begin{array}{c}2156.10- \\
2269.65\end{array}$ & $\begin{array}{c}2010.21- \\
2104.77\end{array}$ & $\begin{array}{c}1061.51- \\
1176.76\end{array}$ & $\begin{array}{c}1694.03- \\
1786.63\end{array}$ & $\begin{array}{c}1520.09- \\
1593.72\end{array}$ \\
\hline Total & 116.56 & 211.74 & 165.60 & 122.82 & 200.65 & 162.98 \\
\hline $95 \% \mathrm{Cl}$ & $\begin{array}{c}113.49- \\
119.71\end{array}$ & $\begin{array}{c}207.72- \\
215.85\end{array}$ & $\begin{array}{c}163.03- \\
168.20\end{array}$ & $\begin{array}{c}119.68- \\
126.04\end{array}$ & $\begin{array}{c}196.76- \\
204.62\end{array}$ & $\begin{array}{c}160.45- \\
165.54\end{array}$ \\
\hline
\end{tabular}

$\mathrm{Cl}$, confidence interval; LVR, Rhineland Regional Council

Since blindness and visual impairment are regarded as very severe disabilities, it can be assumed that they are included in the statistics. A person is entitled to being registered as disabled if they have a disability severity rating of at least $50 \%$. Being registered disabled comes with tax advantages and-depending on the extent of the disability - the right to discounted travel on local and national public transport. As for the LVR, no estimates exist as to the completeness of the SBS dataset either. Because the financial inducement is less attractive, it may be assumed that the rate of nonregistration is somewhat higher in the SBS than in the LVR dataset. Since the classification of the social security offices includes visual impairment as well as blindness, the SBS data have considerably more registrations than the LVR data. The SBS data do not distinguish between blindness and visual impairment, so that these are only available bundled together for the administrative districts of Düsseldorf and Cologne from 1987 to 2005. This contains the categories "blindness or loss of both eyes," "severe visual impairment," and "other visual impairment." The diseases that underlie blindness and visual impairment are largely the same, so trends observed in the LVR dataset should be reflected in the SBS dataset (1).

\section{Calculation of prevalence}

For both datasets, the reference population is the population of the Rhineland in the years in question. All prevalence rates were standardized directly on the basis of the age and sex distribution of the reference population (Rhineland). For the direct standardization, the
German population in 1987 (last census) and the mean population forecasts for 2010 and 2030 were used, to take into account the changing age structure of the population. 95\% confidence intervals were calculated for the stratified (Rhineland) and standardized (Germany) prevalence using the Wilson point method without continuity correction (10). Since it cannot be assumed that all registered blind and visually impaired persons are included in the data, confidence intervals were also calculated for the prevalence rates in the Rhineland. All data are presented exclusively descriptively, so further comparative statistical analyses were not performed.

\section{Results \\ Trends in blindness in the Rhineland}

There was an increase in the number of registered blind people in the LVR dataset from 1978 to 1997 (from 116.8 to 165.6 blind persons per 100000 people, which then remained stable until 2006 (163.1 blind persons per 100000 people in 2006) (Table 1). Age-related macular degeneration (AMD) as the main cause of blindness doubled from $20 \%$ to $40 \%$, and the proportion of those becoming blind as a result of diabetic eye disease also increased (from $7 \%$ to $10 \%$ ). During the same period, glaucoma and optic nerve atrophy as causes of blindness fell from $25 \%$ to $15 \%$. High myopia and retinal detachment as causes of blindness also went down markedly (from $16 \%$ to $5 \%$ [Table 1]).

Stratified by age and sex, it emerges that from 1997 to 2006 the prevalence decreased in the age groups 60 years and older and increased slightly in the age groups 
Prevalence of blindness and visual impairment in the Rhineland, stratified by age and sex, based on the Statistics for Severe Disability 1987-2005 (per 100000 persons)

\begin{tabular}{l|c|c|c|c|c|c|c|c|l} 
& \multicolumn{9}{|c|}{1987} \\
\hline Age group & Male & Female & All & Male & Female & All & Male & Female & All \\
\hline$<\mathbf{2 5}$ years & 46.65 & 37.00 & 41.93 & 45.68 & 41.63 & 43.68 & 40.12 & 31.11 & 35.70 \\
$95 \% \mathrm{Cl}$ & $43.10-$ & $33.80-$ & $39.50-$ & $42.09-$ & $38.10-$ & $41.20-$ & $36.80-$ & $28.13-$ & $33.42-$ \\
& 50.40 & 40.50 & 44.50 & 49.56 & 45.40 & 46.40 & 43.80 & 34.41 & 38.13 \\
\hline $\mathbf{2 5 - 6 0}$ years & 219.65 & 154.07 & 187.30 & 183.75 & 139.94 & 161.99 & 163.24 & 135.20 & 149.23 \\
$95 \% \mathrm{Cl}$ & $213.60-$ & $149.00-$ & $183.30-$ & $178.50-$ & $135.30-$ & $158.50-$ & $158.18-$ & $130.59-$ & $145.80-$ \\
& 225.80 & 159.30 & 191.30 & 189.20 & 144.70 & 165.60 & 168.46 & 139.96 & 152.75 \\
\hline$>60$ years & 1459.63 & 1360.09 & 1396.07 & 1158.01 & 1399.03 & 1296.42 & 965.27 & 1309.32 & 1160.19 \\
$95 \% \mathrm{Cl}$ & $1431.00-$ & $1339.20-$ & $1379.10-$ & $1135.80-$ & $1378.70-$ & $1281.30-$ & $946.65-$ & $1290.34-$ & $1146.70-$ \\
& 1488.90 & 1381.30 & 1413.20 & 1180.70 & 1419.70 & 1311.70 & 984.26 & 1328.59 & 1173.82 \\
\hline Total & 356.68 & 423.53 & 391.55 & 330.30 & 439.07 & 385.42 & 308.36 & 432.41 & 372.11 \\
$95 \% \mathrm{Cl}$ & $351.10-$ & $417.70-$ & $387.50-$ & $325.10-$ & $433.30-$ & $381.50-$ & $303.37-$ & $426.66-$ & $368.28-$ \\
& 362.40 & 429.50 & 395.70 & 335.60 & 445.00 & 389.40 & 313.43 & 438.24 & 375.98
\end{tabular}

below 60, for both men and women (Table 2). In the older age groups ( 60 years and older) it was shown that women are more often affected by blindness, most pronounced for AMD. The confidence intervals for the calculated prevalences are relatively narrow, since a high degree of completeness can be assumed for the LVR data.

The SBS data are divided into somewhat different age classes, which must be taken into account when interpreting them. These data too show a slight decrease in prevalence, from 392 persons (per 100000 people) registered as severely disabled on grounds of blindness or visual impairment in 1987 to 372 (per 100000 people) in 2005 (Table 3). This drop is similar in size among both men and women, although for women the overall prevalence rose somewhat from 1987 to 1997 , and then fell back below the level of 1997 (Table 3).

\section{Trends in blindness and visual impairment in Germany}

Both the LVR and the SBS datasets were standardized for age and sex structure to the German population of 1987, 2010, and 2030 (Table 4). Therefore, the calculated prevalences for Germany are based on the age and sex distribution of the German population in 1987 , 2010 , and 2030. The population predictions up to 2030 assume that the mortality and provision of health care will remain steady at their predicted rates. The slight reduction in the prevalence of blindness and visual impairment shown in the LVR and SBS datasets can be seen in all reference populations (Table 4). Comparison of 1987 and 2030 reveals that as the underlying population ages, the prevalence of blindness and visual impairment goes up markedly as expected (Table 4). Compared with the nonstandardized figures from the LVR and SBS dataset (Table 2, Table 3), however, it appears that the expected increase in blindness and visual impairment due to the aging of the population has not occurred. On the contrary, blindness and visual impairment have gone down.

\section{Discussion}

Based on the demographic trend in Germany, one would expect a marked rise in the prevalence of blindness and visual impairment. Using the datasets of the archive of the blind registry of the LVR and the SBS for Rhineland, however, we could show that the prevalence of blindness did not continue to rise after 1997 (LVR dataset), and the prevalence of blindness and severe visual impairment from 1987 to 2005 (SBS dataset) even fell. This fall can be demonstrated even after standardization to the German population of 1987, 2010, and 2030 and taking the aging of the population into account. The observed decrease in blindness and visual impairment is evidence of tangible success in the prevention of blindness and visual impairment in the population.

Almost no data are available elsewhere in the world on the causes of blindness over a comparably long period of time. As expected, both in Germany $(1,6)$ and in other industrialized countries (11), there has been a marked increase in blindness due to AMD, for which hardly any therapeutic options were available until 2006. The prevalence of diabetes has gone up in all the industrialized countries, partly due to aging and to the increase in obesity, which explains a further increase in blindness due to diabetic eye disease $(12,13)$. So far this increase has been only partly prevented by better general treatment for diabetes and better ophthalmologic diagnosis and treatment. On the other hand, in glaucoma therapy, many new cases of blindness have been prevented by improved diagnostic techniques, the introduction of prostaglandin analogs and topical carboanhydrase inhibitors, and improvements in 
Standardized prevalence of blindness (LVR data) and of blindness and visual impairment (SBS) for Germany in 1987, 1997, and 2005/2006, standardized to the German population for 1987, 2010, and 2030 (per 100000 persons)

\begin{tabular}{|c|c|c|c|c|c|c|c|c|c|}
\hline \multicolumn{10}{|c|}{ Reference population for the standardization } \\
\hline \multicolumn{10}{|c|}{ LVR dataset-blindness } \\
\hline & \multicolumn{3}{|c|}{1987} & \multicolumn{3}{|c|}{2010} & \multicolumn{3}{|c|}{2030} \\
\hline & Male & Female & All & Male & Female & All & Male & Female & All \\
\hline 1997 & 111.77 & 200.77 & 158.09 & 147.89 & 251.98 & 200.91 & 210.28 & 330.64 & 271.58 \\
\hline $95 \% \mathrm{Cl}$ & $\begin{array}{l}85.59- \\
145.95\end{array}$ & $\begin{array}{c}165.80- \\
243.10\end{array}$ & $\begin{array}{l}135.31- \\
184.70\end{array}$ & $\begin{array}{c}117.56- \\
186.04\end{array}$ & $\begin{array}{c}212.01- \\
299.47\end{array}$ & $\begin{array}{c}175.00- \\
230.64\end{array}$ & $\begin{array}{c}173.45- \\
254.93\end{array}$ & $\begin{array}{c}284.36- \\
384.43\end{array}$ & $\begin{array}{c}241.18- \\
305.80\end{array}$ \\
\hline 2006 & 105.58 & 175.65 & 142.05 & 132.21 & 215.61 & 174.69 & 176.78 & 276.78 & 227.72 \\
\hline $95 \% \mathrm{Cl}$ & $\begin{array}{l}80.23- \\
138.93\end{array}$ & $\begin{array}{c}143.15- \\
215.51\end{array}$ & $\begin{array}{c}120.54- \\
167.39\end{array}$ & $\begin{array}{c}103.72- \\
168.52\end{array}$ & $\begin{array}{c}178.89- \\
259.85\end{array}$ & $\begin{array}{c}150.65- \\
202.55\end{array}$ & $\begin{array}{c}143.45- \\
218.08\end{array}$ & $\begin{array}{c}234.85- \\
326.36\end{array}$ & $\begin{array}{c}200.07- \\
259.23\end{array}$ \\
\hline \multicolumn{10}{|c|}{ SBS dataset-blindness and visual impairment } \\
\hline & \multicolumn{3}{|c|}{1987} & \multicolumn{3}{|c|}{2010} & \multicolumn{3}{|c|}{2030} \\
\hline & Male & Female & All & Male & Female & All & Male & Female & All \\
\hline 1987 & 350.20 & 419.72 & 386.38 & 468.52 & 474.33 & 471.48 & 588.21 & 577.90 & 582.97 \\
\hline $95 \% \mathrm{Cl}$ & $\begin{array}{l}301.27- \\
407.26\end{array}$ & $\begin{array}{l}367.80- \\
479.11\end{array}$ & $\begin{array}{c}349.79- \\
426.79\end{array}$ & $\begin{array}{c}411.79- \\
533.03\end{array}$ & $\begin{array}{c}418.22- \\
537.94\end{array}$ & $\begin{array}{c}430.88- \\
515.88\end{array}$ & $\begin{array}{c}524.30- \\
659.88\end{array}$ & $\begin{array}{c}515.56- \\
647.76\end{array}$ & $\begin{array}{r}537.65- \\
632.09\end{array}$ \\
\hline 1997 & 285.61 & 424.23 & 357.76 & 378.74 & 479.92 & 430.27 & 472.85 & 587.33 & 531.03 \\
\hline $95 \% \mathrm{Cl}$ & $\begin{array}{l}241.64- \\
337.57\end{array}$ & $\begin{array}{l}371.89- \\
483.92\end{array}$ & $\begin{array}{c}322.61- \\
396.72\end{array}$ & $\begin{array}{c}328.10- \\
437.18\end{array}$ & $\begin{array}{c}423.46- \\
543.87\end{array}$ & $\begin{array}{c}391.57- \\
472.79\end{array}$ & $\begin{array}{c}415.92- \\
537.57\end{array}$ & $\begin{array}{c}524.45- \\
657.73\end{array}$ & $\begin{array}{r}487.84 \\
578.01\end{array}$ \\
\hline 2005 & 243.96 & 396.70 & 323.46 & 321.33 & 449.31 & 386.52 & 399.13 & 549.85 & 475.72 \\
\hline $95 \% \mathrm{Cl}$ & $\begin{array}{c}203.59- \\
292.31\end{array}$ & $\begin{array}{c}346.20- \\
454.55\end{array}$ & $\begin{array}{c}290.12- \\
360.61\end{array}$ & $\begin{array}{c}274.97- \\
375.50\end{array}$ & $\begin{array}{c}394.80- \\
511.33\end{array}$ & $\begin{array}{c}349.92- \\
426.93\end{array}$ & $\begin{array}{c}347.11- \\
458.93\end{array}$ & $\begin{array}{c}489.12- \\
618.10\end{array}$ & $\begin{array}{r}434.94 \\
520.32\end{array}$ \\
\hline
\end{tabular}

$\mathrm{Cl}$, confidence interval; LVR, Rhineland Regional Council; SBS, Statistics on Severe Disability

ophthalmologic surgical treatment for glaucoma (14). Similarly, improvements in vitreoretinal surgery have led to a considerable reduction in blindness due to high myopia and retinal detachments (15).

Another study, based on the national SBS data from 1993 to 2009, also reported a slight reduction in the prevalence of blindness and visual impairment in Germany once the aging of the population was taken into account (16). Several studies from the US have reported a declining prevalence and incidence of AMD, the cause of most new cases of blindness, especially in younger birth cohorts, and ascribe this to, among other things, a birth cohort effect (17-19). Also, the treatment available since about 2006 for neovascular ('wet') AMD (intravitreal injection of vascular endothelial growth factor [VEGF] inhibitors) appears to lead to a marked reduction in AMD-related blindness (20). Unfortunately, information from the LVR dataset on the main causes of blindness after 2006 are not available to us, so that no conclusions can be drawn about the risk of blindness from AMD from 2006 onward. A study on the incidence of new cases of blindness in Israel reported a very marked drop from 1999 (33.8/100 000) to $2008(16.6 / 100000)$, ascribing this to improved ophthalmologic care and the universal availability of medical services (21).
The aging of the population, however, means that the demand for ophthalmologic care may still be expected to rise markedly. Since even a moderate impairment of vision is associated with considerable disadvantages, loss of quality of life, and costs for the person affected, as well as for their family and for society, more and better research is needed into ophthalmologic and other medical treatments, health care provision, and-above all - into prevention (22). The falling prevalence rates, however, allow the assumption that this trend may be weakened by the improvements in ophthalmologic and general medical care already being achieved.

The LVR dataset that underlies these calculations is, with certain restrictions, representative of more than $10 \%$ of the German population $(1,6)$. In addition, we have access to detailed information about the causes of blindness, which until now were not available in this form for Germany. Another strength of the study is the validation of the data from the archive of the blind registry of the LVR using the Statistics on Severe Disability for the same period and the same reference population.

A limitation of the study is the different underlying definitions of the two sets of data. Another is that we have no information about the causes of blindness in the SBS dataset. As explained in the methods section, 
the completeness of the SBS dataset is probably less than that of the LVR dataset. In both sets of data, it may be assumed that in actuality there are more blind and visually impaired persons than have been registered. However, this remains the same for each year reported, so it will not have a distorting effect on trends over time. Ideally, one would have access to longitudinal data from population-based cohort studies - but so far, these do not exist on any major scale in Germany yet. The standardizations carried out to various reference populations, some of which are based on extrapolations, should be regarded with caution. Almost all projections assume that the mortality and medical provision for the population will remain unchanged; they also assume that there will be no significant migration, and that the disease risk will likewise remain the same. These assumptions match reality only to a limited extent, but they are common practice, since future scenarios taking these factors into account are almost impossible to model chiefly because of a lack of data on which to base them. Nevertheless, the above needs to be taken into account when interpreting the findings of the study.

\section{KEY MESSAGES}

- The prevalence of blindness and visual impairment in Germany has fallen slightly over the past 10 years despite the aging of the population.

- One important factor is probably that ophthalmologic and general medical care has improved over the past few decades.

- Because of the continuing aging of the population, it must be assumed that the need for ophthalmologic care will increase.

- This need for care must be met if a further reduction in the prevalence of blindness and visual impairment is to be achieved.

\section{Conflict of interest statement}

Dr. Finger has received funds into a third-party account from Novartis Pharma. The other authors declare that no conflict of interest exists.

Manuscript received on 3 November 2011, revised version accepted on 7 March 2012.

Translated from the original German by Kersti Wagstaff, MA.

\section{REFERENCES}

1. Finger RP, Fimmers R, Holz FG, Scholl HP: Prevalence and causes of registered blindness in the largest federal state of Germany. Br J Ophthalmol 2011; 95: 1061-7.

2. Finger RP: Blindheit in Deutschland: Dimensionen und Perspektiven. Ophthalmologe 2007; 104: 839-44.
3. Knauer C, Pfeiffer N: Erblindung in Deutschland - heute und 2030. Ophthalmologe 2006; 103: 735-41.

4. Bunce $C$, Wormald R: Causes of blind certifications in England and Wales: April 1999 - March 2000. Eye 2008; 22: 905-11.

5. Farber MD: National Registry for the Blind in Israel: estimation of prevalence and incidence rates and causes of blindness. Ophthalmic Epidemiol 2003; 10: 267-77.

6. Finger RP, Fimmers R, Holz FG, Scholl HP: Incidence of blindness and severe visual impairment in Germany - projections for 2030. Invest Ophthalmol Vis Sci 2011; 52: 4381-9.

7. Foran S, Wang JJ, Rochtchina E, Mitchell P: Projected number of Australians with visual impairment in 2000 and 2030. Clin Experiment Ophthalmol 2000; 28: 143-5.

8. Abou-Gareeb I, Lewallen S, Bassett K, Courtright P: Gender and blind ness: a meta-analysis of population-based prevalence surveys. Ophthalmic epidemiology 2001; 8: 39-56.

9. Bertram B, Hammers H: Die Prävalenz der Erblindungen wegen diabetischer Retinopathie stiegt weiter. Z prakt Augenheilkd 1997; 18: 181-4.

10. Newcombe RG: Two-sided confidence intervals for the single proportion: Comparison of seven methods. Statistics in Medicine 1998; 17 : 857-72

11. Klaver CC, Wolfs RC, Vingerling JR, Hofman A, de Jong PT:Age-specific prevalence and causes of blindness and visual impairment in an older population: the Rotterdam Study. Arch Ophthalmol 1998; 116: 653-8.

12. Rathmann W, Haastert B, Icks A, Lowel H, Meisinger C, Holle R, et al.: High prevalence of undiagnosed diabetes mellitus in Southern Germany: target populations for efficient screening. The KORA survey 2000. Diabetologia 2003; 46: 182-9.

13. Wild S, Roglic G, Green A, Sicree R, King H: Global prevalence of diabetes: estimates for the year 2000 and projections for 2030. Diabetes Care 2004; 27 : 1047-53.

14. Burr J, Azuara-Blanco A, Avenell A: Medical versus surgical interventions for open angle glaucoma. Cochrane Database Syst Rev 2005 (2): CD004399.

15. Bartz-Schmidt U, Szurman P, Wong D, Kirchhof B: Neue Entwicklungen in der chirurgischen Therapie der rheumatogenen Ablatio retinae. Ophthalmologe 2008; 105: 27-36.

16. Wolfram C, Pfeiffer N: Blindness and low vision in Germany 1993-2009. Ophthalmic epidemiology 2012; 19: 3-7.

17. Klein R, Chou CF, Klein BE, Zhang X, Meuer SM, Saaddine JB: Prevalence of age-related macular degeneration in the US population. Arch Ophthalmol 2011; 129: 75-80.

18. Huang GH, Klein R, Klein BE, Tomany SC: Birth cohort effect on prevalence of age-related maculopathy in the Beaver Dam Eye Study. Am J Epidemiol 2003; 157: 721-9.

19. Klein R, Knudtson MD, Lee KE, Gangnon RE, Klein BE: Age-periodcohort effect on the incidence of age-related macular degeneration: the Beaver Dam Eye Study. Ophthalmology 2008; 115: 1460-7.

20. Bloch SB, Larsen M, Munch IC: Incidence of legal blindness from age-related macular degeneration in denmark: year 2000 to 2010. American Journal of Ophthalmology 2012; 153: 209-13.

21. Skaat $A$, Chetrit $A$, Belkin M, Kinori M, Kalter-Leibovici O: Time trends in the incidence and causes of blindness in Israel. American Journal of Ophthalmology 2012; 153: 214-21.

22. Porz G, Scholl HP, Holz FG, Finger RP: Methoden zur Ermittlung persönlicher Krankheitskosten am Beispiel retinaler Erkrankungen. Ophthalmologe 2010; 107: 216-20.

\section{Corresponding author}

Dr. med. Robert P. Finger

Universitätsaugenklinik Bonn

Ernst-Abbe-Str. 2

53127 Bonn, Germany

Robert.Finger@ukb.uni-bonn.de 